\title{
Temperature-related mortality impacts under and beyond Paris Agreement climate change scenarios
}

\section{Ana Maria Vicedo-Cabrera, et al. [full author details at the end of the article]}

Received: 15 May 2018 / Accepted: 3 August 2018 / Published online: 13 September 2018

(C) The Author(s) 2018

\begin{abstract}
The Paris Agreement binds all nations to undertake ambitious efforts to combat climate change, with the commitment to "hold warming well below $2{ }^{\circ} \mathrm{C}$ in global mean temperature (GMT), relative to pre-industrial levels, and to pursue efforts to limit warming to $1.5^{\circ} \mathrm{C}$ ”. The $1.5^{\circ} \mathrm{C}$ limit constitutes an ambitious goal for which greater evidence on its benefits for health would help guide policy and potentially increase the motivation for action. Here we contribute to this gap with an assessment on the potential health benefits, in terms of reductions in temperature-related mortality, derived from the compliance to the agreed temperature targets, compared to more extreme warming scenarios. We performed a multi-region analysis in 451 locations in 23 countries with different climate zones, and evaluated changes in heat and coldrelated mortality under scenarios consistent with the Paris Agreement targets $\left(1.5\right.$ and $\left.2{ }^{\circ} \mathrm{C}\right)$ and more extreme GMT increases $\left(3\right.$ and $4{ }^{\circ} \mathrm{C}$ ), and under the assumption of no changes in demographic distribution and vulnerability. Our results suggest that limiting warming below $2{ }^{\circ} \mathrm{C}$ could prevent large increases in temperature-related mortality in most regions worldwide. The comparison between 1.5 and $2{ }^{\circ} \mathrm{C}$ is more complex and characterized by higher uncertainty, with geographical differences that indicate potential benefits limited to areas located in warmer climates, where direct climate change impacts will be more discernible.
\end{abstract}

Keywords Climate change $\cdot$ Mortality $\cdot$ Temperature $\cdot$ Projections

\section{Background}

The Paris Agreement, adopted in December 2015 under the auspices of the United Nations Framework Convention on Climate Change (UNFCCC), is a turning point in negotiations to limit the potential damages of climate change. An agreement was reached on an ambitious long-term goal to limit warming from pre-industrial levels "well below" a $2-^{\circ} \mathrm{C}$ increment in global mean temperature (GMT), and to pursue efforts to limit it to $1.5^{\circ} \mathrm{C}$ (UNFCCC 2015a; UNFCCC 2015b). The UNFCCC invited the Intergovernmental Panel on Climate Change (IPCC) to provide a special report in 2018 on the impacts of $1.5-$ vs. $2-{ }^{\circ} \mathrm{C}$ warming, to determine the avoided impacts of further reductions in greenhouse gas emissions. This report

Electronic supplementary material The online version of this article (https://doi.org/10.1007/s10584-0182274-3) contains supplementary material, which is available to authorized users. 
will include multisectoral assessments of the regional-scale consequences for society and environment of different degrees of warming, with comprehensive evaluations of potential impacts. Non-optimal outdoor temperatures will be included in the assessment of impacts on human health (Seneviratne et al. 2016). Most studies projecting the health risks of temperature extremes were performed in country-specific settings, mainly in high-income regions (Sanderson et al. 2017). The majority of these studies focused on heat-related deaths, and did not consider cold-related mortality, which may be reduced as temperature continues to increase (Wang et al. 2016). Our recent multi-country health impact projection analysis, the largest of its kind, investigated trends in temperature-related mortality under various greenhouse gas (GHG) emission trajectories (Gasparrini et al. 2017). However, these studies offered little evidence on the comparative risks under warming scenarios based on specific GMT targets, such as those under the Paris Agreement. The present contribution addresses this research gap by assessing the excess mortality attributable to non-optimal temperature projected across various geographical and climate regions under climate change scenarios corresponding to 1.5 and $2{ }^{\circ} \mathrm{C}$ increases in GMT, and by comparing them with more extreme warming scenarios corresponding to 3 and $4{ }^{\circ} \mathrm{C}$ increases.

\section{Brief description of the method}

We projected temperature-related excess mortality in 451 locations from 23 countries across the globe characterized by a wide range of climatic conditions, included in the Multi-Country Multicity (MCC) Collaborative Research Network (http://mccstudy.lshtm.ac.uk/) (Table 1, Fig. S1, and Supplementary Material S1). We applied a methodology developed in a previous study on trends in temperature-mortality projections performed within the same collaborative network (Gasparrini et al. 2017). Here in this section, we provide a brief description of this methodological framework. For a more detailed explanation on the different analytical steps, refer to the Supplementary Material S2 and to a previous work (Gasparrini et al. 2017). In brief, we firstly estimated the location-specific exposure-response relationship between observed daily temperature and mortality counts using historical data collected through the MCC Network. We then projected temperature-related excess mortality, using the modeled daily series of temperature and mortality, under scenarios consistent with $1.5,2,3$, and $4{ }^{\circ} \mathrm{C}$ increases in GMT above pre-industrial levels, assuming no change in demographics or population vulnerability. Thus, results are expressed as function of specific warming levels, instead of calendar periods under specific emission pathways as done in the previous publication (Gasparrini et al. 2017). These warming scenarios were defined using 20-year windows of modeled daily temperature within 1990-2099 corresponding to specific GMT increases. These "time-slices" were obtained from three global climate models (GCMs, specifically HadGEM2-ES (Jones et al. 2011), IPSL-CM5A-LR (Mignot and Bony 2013), and MIROC-ESM-CHEM (Watanabe et al. 2011)) under Representative Concentration Pathway 8.5 (RCP8.5). The combination of RCP8.5 and the three GCMs was selected to ensure a warming level of up to $4{ }^{\circ} \mathrm{C}$ in GMT over the current century. The time slices were identified in each GCM following a procedure detailed elsewhere (Schleussner et al. 2016). See Table S2 for the specific periods, Table 1, and Fig. S2 for the geographical distribution of the location-specific GMT increase from 1.5 to $2{ }^{\circ} \mathrm{C}$ and Fig. S3 for the overall GCM-ensemble trends. This time-slice approach is justified given that little evidence for scenario dependence was found for temperaturerelated indices and a warming of up to $4{ }^{\circ} \mathrm{C}$ (Seneviratne et al. 2016; James et al. 2017). At the same time, by using location-specific series, we account for differential increases in temperature 
across geographical areas for each GMT scenario. Location-specific excess mortality, expressed in terms of attributable fractions for cold (below the minimum mortality temperature, MMT) and heat (above MMT), in each 20-year window were averaged across GCMs to obtain the corresponding ensemble estimate in each scenario (Gasparrini and Leone 2014).

We estimated differences in temperature-related excess mortality in 2,3 and $4{ }^{\circ} \mathrm{C}$ scenarios relative to $1.5^{\circ} \mathrm{C}$ for heat, cold, and total (net, i.e., the summed contribution of heat and cold). Heterogeneity was explored by aggregating absolute and differences in excess mortality for each scenario by country, geographic region, and climate zone (defined by the first letter of the Köppen-Geiger classification (Kottek et al. 2006)).

\section{Results}

Figure 1 displays the projected changes in excess mortality by comparing the $1.5-$ vs $2-{ }^{\circ} \mathrm{C}$ increase scenarios in each country, geographic region, and climate zone (actual numbers in Tables S3-S6). Overall, an increase from 1.5 to $2{ }^{\circ} \mathrm{C}$ in GMT could generate a substantial rise in heat-related mortality in most countries included in the analysis. Specifically, assuming no changes in population and vulnerability, heat-mortality impacts could increase between +0.11 and $+2.13 \%$, with most countries in South Europe and South-East Asia showing increments above $+1 \%$. In contrast, cold-related mortality could decrease in all countries between -0.27 and $-0.98 \%$. These decrements are of a lower magnitude compared to the corresponding heatrelated risks, producing a net increase in excess mortality in about half of the countries but with large uncertainty in most of them. For instance, only Italy and Spain, the two countries in the South of Europe included in the study, could face a significant net increase in total excess temperature-related mortality of about +0.66 and $+0.77 \%$, respectively. Similar or larger but not statistically significant increases, reaching $+1.15 \%$, could be observed in other warm countries in South-East Asia, such as the Philippines, Thailand, and Vietnam, despite having different climate conditions (Fig. 1, Fig. S1, Table 1). In contrast, total excess mortality could decrease in cooler areas such as North Europe and East Asia. For example, Ireland and Japan could register a small decrease between -0.51 and $-0.27 \%$. Other large countries (Canada, USA, and Chile), and some countries located in central areas such as Czech Republic and Moldova, might not face substantial changes in total excess mortality. However, many of the net change estimates are not statistically significant, reflecting the uncertainty in the estimates.

Figure 2 illustrates the trends in differences in excess mortality by geographic region and climatic zone projected under other warming scenarios, including those beyond the Paris Agreement targets, corresponding to increases in GMT of 2,3 , and $4{ }^{\circ} \mathrm{C}$, relative to $1.5^{\circ} \mathrm{C}$ (figures in Tables S3-S6). As expected, we observed a common pattern of rising mortality associated with heat and a moderate attenuation in cold-related impacts. Under more extreme scenarios, most regions could experience considerably larger heat-mortality risks that would not be balanced by the projected decreases in cold-related excess mortality. Specifically, central and southern regions of America, Europe, and East-Asia are projected to experience increases in heat-related mortality impacts ranging between +3.53 and $+8.86 \%$ in the most extreme $4-^{\circ} \mathrm{C}$ scenario, while cooler regions in Europe and Asia could face smaller increases below $+2 \%$. In the latter regions, the contribution of the reduction in cold-related mortality impacts would be similar to the increase observed for heat, ranging between -1.88 and $2.23 \%$, translating into small or even null and non-significant net reductions in total excess mortality. The most affected areas in terms of large increases in net temperature-mortality 


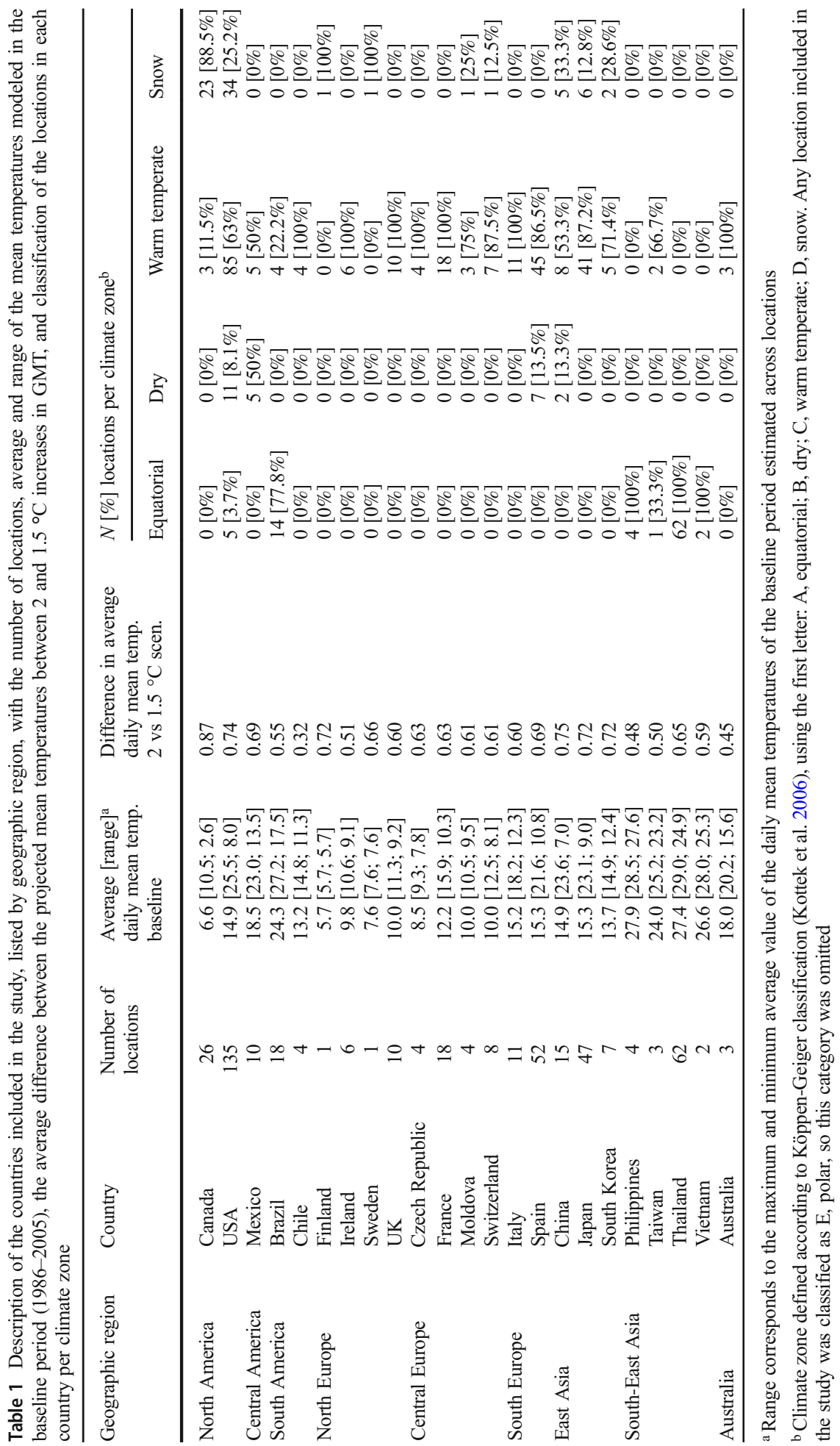




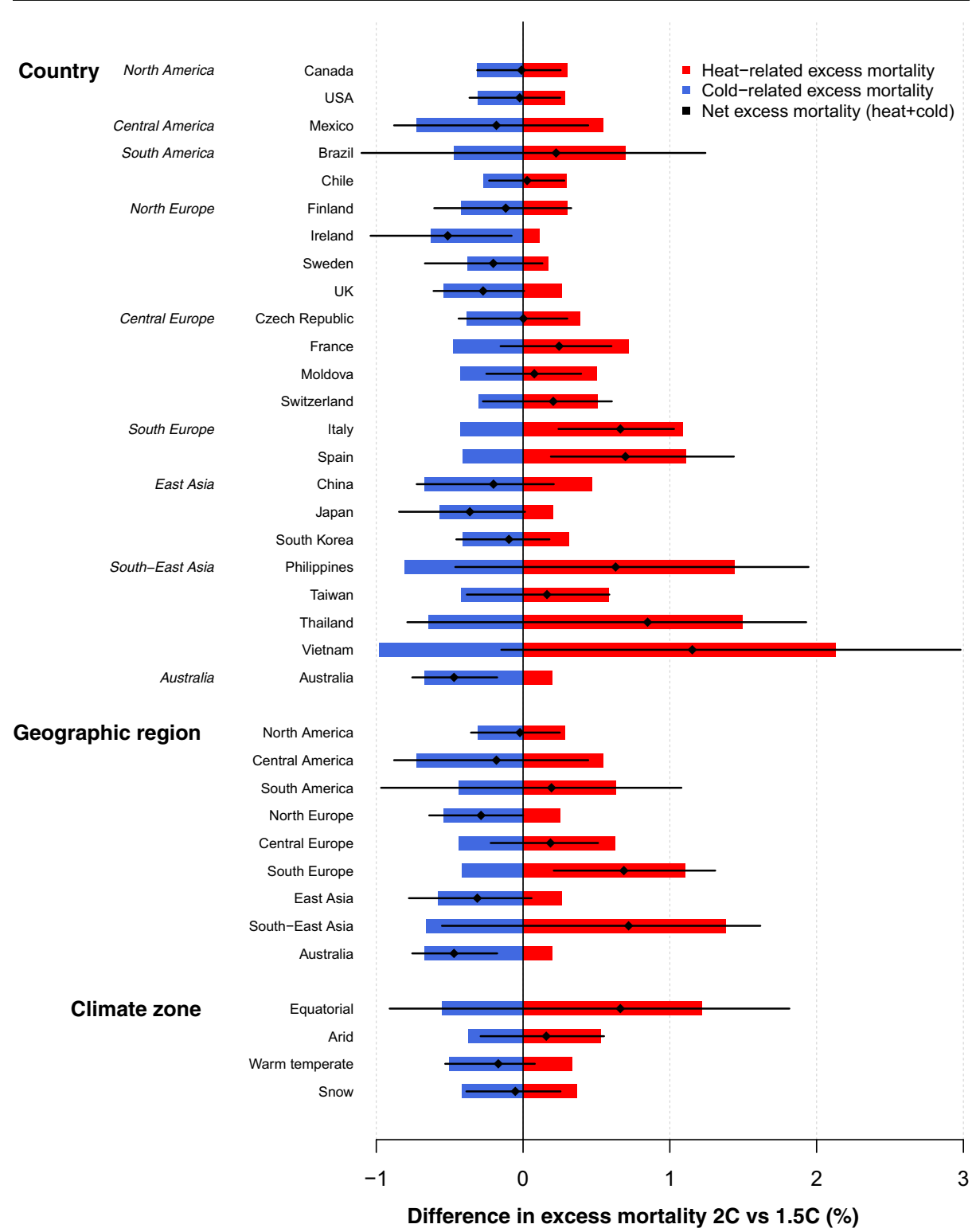

Fig. 1 Change in excess mortality from 1.5 - to $2-{ }^{\circ} \mathrm{C}$ scenario by country, geographic region and climate zone. Red and blue bars represent changes in heat (above minimum mortality temperature) and cold (below minimum mortality temperature) excess mortality, respectively, and black diamond and bar correspond to net excess mortality (heat+cold) and $95 \%$ confidence interval.

impacts would be again the warmest regions in the south of Europe and South-East-Asia (+ 4.41 and $+7.07 \%)$, and in a smaller magnitude in South America and Central Europe $(+2.60$ and $+2.63 \%)$. However, estimates on net changes are highly uncertain for most of the regions and warming levels, showing statistically significant results only for the central and southern European regions. A different pattern is observed for Australia, with negative net changes in excess mortality across the warming scenarios. This would be due to the milder temperature 


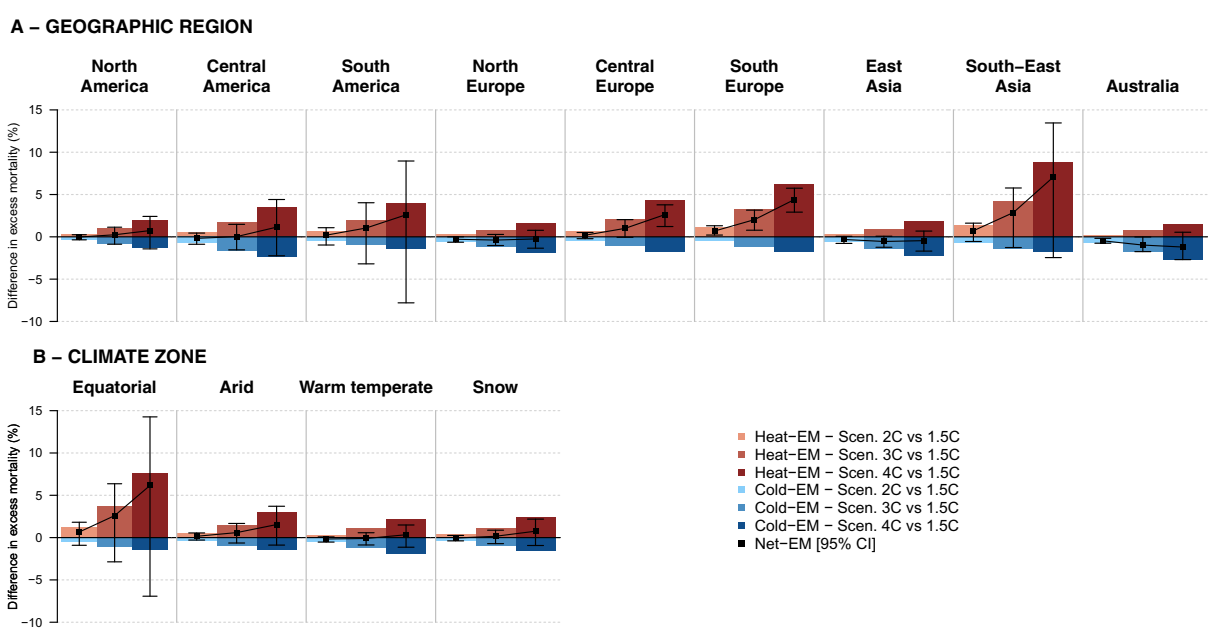

Fig. 2 Trends in changes in excess mortality projected for warming in 2,3 and $4{ }^{\circ} \mathrm{C}$, relative to $1.5{ }^{\circ} \mathrm{C}$, by geographic region and climate zone. Red and blue bars represent changes in heat (above minimum mortality temperature) and cold (below minimum mortality temperature) excess mortality, respectively, while black squares correspond to net excess mortality (heat+cold) and its $95 \%$ confidence interval.

projections obtained for this region, compared to other areas of similar climate, as shown in Fig. S3 and in a previous work (Gasparrini et al. 2017).

The pattern of results suggests an association between projected total temperature impacts and current climate conditions. This is particularly clear in Europe and Asia, where the impact of a change in temperature applied to the current population shows moderate decreases in excess mortality in the colder areas of the north, nearly null changes or small increases in the temperate central areas, and larger increases in warmer southern regions. This pattern is better illustrated in Fig. 3 showing the geographical distribution of the location-specific estimates for the 2 - vs $1.5-{ }^{\circ} \mathrm{C}$ difference. We can also observe a within-country positive gradient from temperate to warmer or equatorial areas in Brazil, although this was not clear in other countries in Central America and USA; the results obtained by different climate zones confirm this gradient (Figs. 1 and 2, bottom panel). Although imprecise, our projections indicate that locations in equatorial climates could experience $\mathrm{a}+0.66 \%$ increase in total excess mortality from 1.5 to $2{ }^{\circ} \mathrm{C}$ warming, followed by a smaller $+0.16 \%$ increase in arid zones, while cooler regions (warm temperate and snow climates) could register a decrease or close-to-null change in total excess temperature-related mortality (Fig. 1, Table S6) based on the current population. Similarly, equatorial locations would be the most affected areas by far under more extreme scenarios, experiencing an increment in total mortality impacts above $+6 \%$ if GMT increases by $4{ }^{\circ} \mathrm{C}$.

Figure S4 shows the results from a sensitivity analysis in which we compare the GCMspecific and ensemble excess mortality estimated for each geographic area for $1.5-^{\circ} \mathrm{C}$ warming scenario. We observe little variation across models, thus confirming that impact calculation does not depend on the timing in which each GCM reach a specific warming level, and therefore on the choice of specific climate models or emission pathways. 


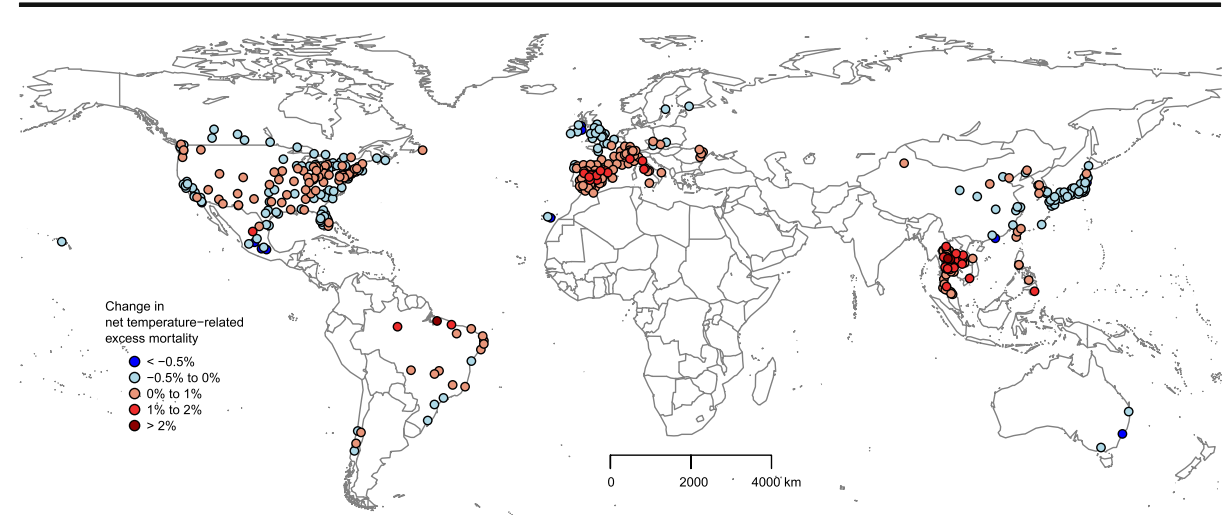

Fig. 3 Map showing the geographical distribution of the location-specific total excess mortality change between 1.5 and $2{ }^{\circ} \mathrm{C}$ scenarios

\section{Study context and interpretation of the results}

This study investigates the potential temperature-mortality impacts projected under specific climate change scenarios consistent with the Paris Agreement. Projections are presented as a function of GMT rise, instead of climate trajectories or emission scenarios as in previously published health impact assessments. Our approach is consistent with the framework of the Paris Agreement, which sets explicit temperature targets but does not define specific timelines or mitigation plans. It is therefore implicit that the same GMT rise can be reached under different development pathways and mitigation policies, as previously demonstrated (Seneviratne et al. 2018). Coherently, impact estimates are likely to be largely independent from the choice of alternative GCM/RCP combinations to select the time slices corresponding to a specific GMT increase, as shown in our analysis (Fig. S4). While this framework offers a straightforward way to quantify target-related impacts, it does not permit the integration of other factors that are likely to modify future health burdens, such as demographic changes and adaptation strategies, as the timing and socio-economic pathways leading to the related GMT increases can vary. By contrast, the applied methodology is based on clear assumptions defining simplified scenarios of stable populations and no-adaptation. Although we acknowledge that these are unrealistic representations of plausible futures, these simplified scenarios facilitate the proper interpretation of the results, as the impact due to global warming can be disentangled from the contribution of other factors. Consistently, our estimates should not be considered predictions of future mortality, but projections of hypothetical health impacts based on current socio-economic conditions, population structure and level of vulnerability. While recognizing these limitations, findings from this study can serve as a basis in the ongoing discussions on the implementation of the Paris Agreement, and can be then extended and refined to assess more specific scenarios that take into account detailed mitigation strategies and underlying changes in baseline populations and temperature-related risks.

Other interpretational issues should be also considered. For example, our projections are limited to the direct acute impact of heat and cold on mortality, and do not consider potentially larger impacts due to indirect pathways (e.g., sea-level rise or food production). Likewise, although the present study covers a large number of locations from different regions worldwide, it is not entirely representative of each geographic region or climate zone. For instance, temperature-related impacts in other warm regions such as Africa, the Arabian Peninsula, or other countries in South-East Asia 
such as India, were not explored due to the lack of observed temperature-mortality data. Indeed, these highly populated and mostly poor areas are particularly vulnerable to climate change, and it is expected that populations in these locations could suffer from more severe extreme heat events (Harrington et al. 2016; Russo et al. 2016; Lelieveld et al. 2016; Mazdiyasni et al. 2017).

We applied an analytical framework based on advanced, established statistical techniques that enabled us to model complex temperature-mortality associations and project the corresponding impacts under clearly defined warming scenarios (Gasparrini et al. 2017). Specifically, these methods allow modeling non-linear and lagged epidemiological relationships, capturing geographical differences, and separating the contributions of cold and heat temperatures (Gasparrini et al. 2015) (Supplementary Material S2). However, we also observe a large uncertainty in our estimates, particularly those for the net impacts and more extreme scenarios. The imprecision is attributed to variability in the climate models and to estimates of the exposure-response curves. In the latter, the uncertainty and potential biases generated in extrapolating the functions beyond the observed temperature range are not accounted for (Ebi and Rocklöv 2014; Benmarhnia et al. 2014). However, the impact of such extrapolation is unlikely to be substantial, because on average only 1.7 and $3.2 \%$ of heat days temperature were above the maximum observed in each 1.5- and $2-{ }^{\circ} \mathrm{C}$ scenario (Table S7). Likewise, we should acknowledge that the results would likely be even less precise if other important sources of uncertainty, such as accounting for adaptation, were considered in the present analysis (Gosling et al. 2017).

\section{Conclusion}

In conclusion, our findings suggest that, assuming no changes in population and vulnerability and consistent with the thresholds agreed in Paris, lower increases in GMT would reduce temperaturerelated mortality in most regions of the world. As reported in the 5th IPCC assessment report (IPCC 2014) and shown in the present study, the $2-{ }^{\circ} \mathrm{C}$ long-term temperature goal should not be considered as "safe", because warming at this level could still produce increments in mortality. However, conclusions on the additional benefits of an extra $0.5^{\circ} \mathrm{C}$ decrease in GMT rise are not straightforward, with the comparison of 1.5 vs $2{ }^{\circ} \mathrm{C}$ affected by larger uncertainty and showing important geographical variability. Specifically, we found indications of a net increase in total mortality in cooler regions when restricting warming to $1.5^{\circ} \mathrm{C}$, due to the large component of coldrelated mortality. In contrast, warmer areas could still experience a net decrease due to the relative rise in heat-related mortality. These patterns seem to follow a within-continent gradient according to the prevalent climate, with populations living in warmer areas, especially with equatorial climates, benefitting the most from stricter mitigation policies. Recent studies suggest that the direct consequences of climate change will be more visible in these tropical regions, not only in terms of increases in average temperature and a higher likelihood of more intense extreme-heat events, but also more frequent extreme weather episodes (i.e., droughts and floods) and more severe indirect effects (i.e., changes in crop yields) (Schleussner et al. 2016; Mora et al. 2017). In fact, these regions include the most populated areas worldwide and, in general, the most vulnerable to climate change, with a limited capacity for adaptation due to lack of infrastructural, financial, and technological resources (Smith et al. 2014).

Acknowledgements This work was primarily supported by the Medical Research Council-UK (Grant ID: MR/ M022625/1) and by the Natural Environment Research Council UK (Grant ID: NE/R009384/1). The following individual grants also supported this work: YG was supported by the Career Development Fellowship of Australian 
National Health and Medical Research Council (Grant ID: APP1107107); AT was supported by the Ministry of Education of Spain (Grant ID: PRX12/00515); JK and AU was supported by the Czech Science Foundation (Grant ID: 16-22000S); JJKJ and NRIR were supported by the Research Council for Health, Academy of Finland (Grant ID: 266314); YLG was supported by the National Health Research Institutes of Taiwan (Grant ID: NHRI-EM-106SP03); MLB was supported by a U.S. Environmental Protection Agency Assistance Agreement awarded to Yale University (Grant ID: 83587101); YH, MH, XS, and TND were supported by the Environment Research and Technology Development Fund (S-14) of the Environmental Restoration and Conservation Agency; YH, LG, and HK were supported by the Global Research Lab (\#K21004000001-10A0500-00710) through the National Research Foundation of Korea funded by the Ministry of Science, ICT and future planning. BA was supported by the National Institute for Health Research Health Protection Research Unit (NIHR HPRU) in Environmental Change and Health. C.F.S. acknowledges support by the German Federal Ministry for the Environment (16_II_148_Global_A_IMPACT) and by German Federal Ministry for Education and Research (01LS1613A).

Authors contribution $\mathrm{AG}, \mathrm{YG}, \mathrm{MH}$, and BA set up the collaborative network. AG, AMVC, FS, and KE designed the study. AG, AMVC, and FS coordinated the work. AMVC took the lead in drafting the manuscript and interpreting the results. AG and FS developed the statistical methods. AMVC, AG, and FS conducted the statistical analysis. AG, KE, BA, AH, FS, and VH provided substantial scientific input in interpreting the results and drafting the manuscript. YG, ST, MSZSC, PHNS, EL, PMC, NVO, HKan, SO, JK, JJKJ, NRIR, MP, PGG, AZek, PM, MS, MHas, YH, MHur, JCCC, XS, HKim, AT, CI, BF, DOA, MSR, YLG, CFW, AZan, JS, MLB, TND, DDV, CH, SV, and SH provided the data, and contributed to the interpretation of the results and to the submitted version of the manuscript.

\section{Compliance with ethical standards}

Competing financial interests We declare that we have no competing financial interests.

Open Access This article is distributed under the terms of the Creative Commons Attribution 4.0 International License (http://creativecommons.org/licenses/by/4.0/), which permits unrestricted use, distribution, and reproduction in any medium, provided you give appropriate credit to the original author(s) and the source, provide a link to the Creative Commons license, and indicate if changes were made.

\section{References}

Benmarhnia T, Sottile M-F, Plante C et al (2014) Variability in temperature-related mortality projections under climate change. Environ Health Perspect 122:1293-1298. https://doi.org/10.1289/ehp.1306954

Ebi KL, Rocklöv J (2014) Climate change and health modeling: horses for courses. Glob Health Action 7:24154

Gasparrini A, Leone M (2014) Attributable risk from distributed lag models. BMC Med Res Methodol 14:55. https://doi.org/10.1186/1471-2288-14-55

Gasparrini A, Guo Y, Hashizume M et al (2015) Mortality risk attributable to high and low ambient temperature: a multicountry observational study. Lancet Lond Engl 386:369-375. https://doi.org/10.1016/S0140-6736(14 )62114-0

Gasparrini A, Guo Y, Sera F et al (2017) Projections of temperature-related excess mortality under climate change scenarios. Lancet Planet Health 1:e360-e367. https://doi.org/10.1016/S2542-5196(17)30156-0

Gosling SN, Hondula DM, Bunker A et al (2017) Adaptation to climate change: a comparative analysis of modeling methods for heat-related mortality. Environ Health Perspect 125:087008. https://doi.org/10.1289 /EHP634

Harrington LJ, Frame DJ, Fischer EM et al (2016) Poorest countries experience earlier anthropogenic emergence of daily temperature extremes. Environ Res Lett 11:055007. https://doi.org/10.1088/1748-9326/11/5/055007

IPCC Climate change 2014: synthesis report, contributions of working groups I, II and III to the fifth assessment report of the intergovernmental panel on climate change [Core Writing Team, Pachauri RK, Meyer LA, editors]. Geneva, Switzerland; 2014. XX p 
James R, Washington R, Schleussner C-F, et al (2017) Characterizing half-a-degree difference: a review of methods for identifying regional climate responses to global warming targets. Wiley Interdiscip Rev Clim Change 8:n/a-n/a. doi: https://doi.org/10.1002/wcc.457

Jones CD, Hughes JK, Bellouin N et al (2011) The HadGEM2-ES implementation of CMIP5 centennial simulations. Geosci Model Dev 4:543-570. https://doi.org/10.5194/gmd-4-543-2011

Kottek M, Grieser J, Beck C et al (2006) World map of the Köppen-Geiger climate classification updated. Meteorol Z:259-263. https://doi.org/10.1127/0941-2948/2006/0130

Lelieveld J, Proestos Y, Hadjinicolaou P et al (2016) Strongly increasing heat extremes in the Middle East and North Africa (MENA) in the 21st century. Clim Chang 137:245-260. https://doi.org/10.1007/s10584-0161665-6

Mazdiyasni O, AghaKouchak A, Davis SJ et al (2017) Increasing probability of mortality during Indian heat waves. Sci Adv 3:e1700066. https://doi.org/10.1126/sciadv.1700066

Mignot J, Bony S (2013) Presentation and analysis of the IPSL and CNRM climate models used in CMIP5. Clim Dyn 40:2089-2089. https://doi.org/10.1007/s00382-013-1720-1

Mora C, Dousset B, Caldwell IR et al (2017) Global risk of deadly heat. Nat Clim Change advance online publication. https://doi.org/10.1038/nclimate3322

Russo S, Marchese AF, Sillmann J, Immé G (2016) When will unusual heat waves become normal in a warming Africa? Environ Res Lett 11:054016. https://doi.org/10.1088/1748-9326/11/5/054016

Sanderson M, Arbuthnott K, Kovats S, et al (2017) The use of climate information to estimate future mortality from high ambient temperature: a systematic literature review. PLoS One 12:. doi: https://doi.org/10.1371 /journal.pone.0180369

Schleussner C-F, Lissner TK, Fischer EM et al (2016) Differential climate impacts for policy-relevant limits to global warming: the case of $1.5^{\circ} \mathrm{C}$ and $2{ }^{\circ} \mathrm{C}$. Earth Syst Dynam 7:327-351. https://doi.org/10.5194/esd-7327-2016

Seneviratne SI, Donat MG, Pitman AJ et al (2016) Allowable CO2 emissions based on regional and impactrelated climate targets. Nature 529:477-483. https://doi.org/10.1038/nature16542

Seneviratne SI, Rogelj J, Séférian R et al (2018) The many possible climates from the Paris Agreement's aim of $1.5^{\circ} \mathrm{C}$ warming. Nature 558:41-49. https://doi.org/10.1038/s41586-018-0181-4

Smith KR, Woodward A, Campbell-Lendrum D et al (2014) Human health: impacts, adaptation, and co-benefits. In: Field CB, Barros VR, Dokken DJ, Mach KJ, Mastrandrea MD, Bilir TE, Chatterjee M, Ebi KL, Estrada YO, Genova RC, Girma B, Kissel ES, Levy AN, MacCracken S, Mastrandrea PR, White LL (eds) Climate change 2014: impacts, adaptation, and vulnerability. Part A: global and sectoral aspects. Contribution of working group II to the fifth assessment report of the intergovernmental panel on climate change. Cambridge University Press, Cambridge, United Kingdom and New York, NY, USA, pp 709-754

UNFCCC (2015a) Report of the Conference of the Parties on its twenty-first session, held in Paris from 30 November to 11 December 2015. Addendum Part two: Action taken by the Conference of the Parties at its twenty-first session (https://unfccc.int/resource/docs/2015/cop21/eng/10.pdf). Accessed 15 May 2018

UNFCCC (2015b) Report of the structured expert dialogue on the 2013-2015 review. (https://unfccc. int/resource/docs/2015/sb/eng/inf01.pdf). Accessed 15 May 2018

Wang Y, Shi L, Zanobetti A, Schwartz JD (2016) Estimating and projecting the effect of cold waves on mortality in 209 US cities. Environ Int 94:141-149. https://doi.org/10.1016/j.envint.2016.05.008

Watanabe S, Hajima T, Sudo K et al (2011) MIROC-ESM 2010: model description and basic results of CMIP520c3m experiments. Geosci Model Dev 4:845-872. https://doi.org/10.5194/gmd-4-845-2011

\section{Affiliations}

Ana Maria Vicedo-Cabrera ${ }^{1}$ - Yuming Guo ${ }^{2,3}$ - Francesco Sera ${ }^{1}$ - Veronika Huber ${ }^{4,5}$.

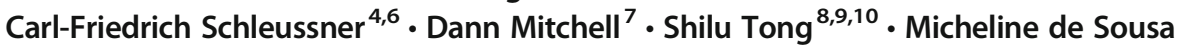
Zanotti Stagliorio Coelho ${ }^{11}$ • Paulo Hilario Nascimento Saldiva ${ }^{11}$ • Eric Lavigne ${ }^{12,13}$. Patricia Matus Correa ${ }^{14}$ - Nicolas Valdes Ortega ${ }^{14}$. Haidong Kan ${ }^{15}$ - Samuel Osorio ${ }^{16}$. Jan Kyselý ${ }^{17,18}$ - Aleš Urban ${ }^{17}$ • Jouni J. K. Jaakkola ${ }^{19}$ - Niilo R. I. Ryti ${ }^{19}$ • Mathilde Pascal $^{20}$ • Patrick G. Goodman ${ }^{21}$ - Ariana Zeka ${ }^{22}$ - Paola Michelozzi ${ }^{23}$ - Matteo Scortichini $^{23}$ - Masahiro Hashizume ${ }^{24}$ - Yasushi Honda ${ }^{25}$. Magali Hurtado-Diaz ${ }^{26}$. Julio $\mathrm{Cruz}^{26}$ - Xerxes Seposo ${ }^{27,28} \cdot$ Ho Kim $^{29}$ - Aurelio Tobias ${ }^{30}$ - Carmen Íñiguez ${ }^{31}$. Bertil Forsberg ${ }^{32}$ - Daniel Oudin Åström ${ }^{32}$ - Martina S. Ragettli ${ }^{33,34}$ • Martin Röösli ${ }^{33,34}$. 
Yue Leon Guo ${ }^{35}$ - Chang-fu Wu ${ }^{36}$ - Antonella Zanobetti ${ }^{37} \cdot$ Joel Schwartz ${ }^{37}$ - Michelle

L. Bell $^{38}$ - Tran Ngoc Dang ${ }^{39,40}$. Dung Do Van ${ }^{39}$. Clare Heaviside ${ }^{1,41}$. Sotiris Vardoulakis $^{1,42} \cdot$ Shakoor Hajat $^{1} \cdot$ Andy Haines $^{1} \cdot$ Ben Armstrong ${ }^{1} \cdot$ Kristie L. Ebi $^{43}$. Antonio Gasparrini ${ }^{1}$

Ana Maria Vicedo-Cabrera

ana.vicedo-cabrera@1shtm.ac.uk

1 Department of Public Health, Environments and Society, London School of Hygiene \& Tropical Medicine, Keppel St, Bloomsbury, London WC1E 7HT, UK

2 Department of Epidemiology and Preventive Medicine, School of Public Health and Preventive Medicine, Monash University, 99 Commercial Road, Melbourne, VIC 3004, Australia

3 Division of Epidemiology and Biostatistics, School of Population Health, University of Queensland, St Lucia, Brisbane, QLD 4072, Australia

4 Potsdam Institute for Climate Impact Research, Telegrafenberg, 14473 Potsdam, Germany

5 Universidad Pablo de Olavide, Carretera de Utrera, 41013 Sevilla, Spain

6 Climate Analytics, Ritterstraße 3, 10969 Berlin, Germany

7 School of Geographical Sciences, University of Bristol, University Road, Bristol BS8 1SS, UK

8 School of Public Health and Institute of Environment and Human Health, Anhui Medical University, Meishan Road, Hefei 81 230032, China

9 Shanghai Children's Medical Centre, Shanghai Jiao-Tong University, 1678 Dongfang Rd, Shanghai 200127, China

10 School of Public Health and Social Work, Queensland University of Technology, 2 George St, Brisbane City, QLD 4000, Australia

11 Institute of Advanced Studies, University of São Paulo, Rua Praça do Relógio, 109, Building K, 5th floor, Cidade Universitária, ZC, São Paulo, São Paulo 05508-970, Brazil

12 School of Epidemiology and Public Health, University of Ottawa, 600 Peter Morand Crescent, Ottawa K1G 5Z3, Canada

13 Healthy Environments and Consumer Safety Branch, Health Canada, Ottawa, Canada

14 Department of Public Health, Universidad de los Andes, Mons. Alvaro del Portillo 12, 455 Santiago, Chile

15 Department of Environmental Health, School of Public Health, Fudan University, 138 Yi xue yuan Road, Shanghai 200032, China

16 Department of Environmental Health, University of São Paulo, Av. Dr. Arnaldo, 715 - Cerqueira César, São Paulo, São Paulo 03178-200, Brazil

17 Institute of Atmospheric Physics, Academy of Sciences of the Czech Republic, Bocni, 140114131 Prague, Czech Republic

18 Faculty of Environmental Sciences, Czech University of Life Sciences, Kamycka, 12916521 Prague, Czech Republic

19 Center for Environmental and Respiratory Health Research, University of Oulu, Aapistie 5B, FI90014 Oulu, Finland

20 Santé Publique France, French National Public Health Agency, 12 rue du Val d'Osne, 94415 Saint Maurice, France

21 School of Physics, Dublin Institute of Technology, Kevin Street 2, Dublin D08 X622, Ireland

22 Institute of Environment, Health and Societies, Brunel University London, Kingston Ln, Uxbridge, London UB8 3PH, UK 
23 Department of Epidemiology, Lazio Regional Health Service, Via Cristoforo Colombo, 11200147 Rome, Italy

24 Department of Pediatric Infectious Diseases, Institute of Tropical Medicine, Nagasaki University, 1-12-4 Sakamoto Nagasaki, Nagasaki 852-8523, Japan

25 Faculty of Health and Sport Sciences, University of Tsukuba, 1-1-1 Tennodai, Tsukuba 305-8574, Japan

26 Department of Environmental Health, National Institute of Public Health, Universidad No. 655 Colonia Santa María Ahuacatitlán, Cerrada Los Pinos y Caminera, 62100 Cuernavaca, Morelos, Mexico

27 Department of Environmental Engineering, Graduate School of Engineering, Kyoto University, Kyoudai Katsura Campus, Nishikyou Ward, Kyoto 615-8540, Japan

28 Department of Global Ecology, Graduate School of Global Environmental Studies, Yoshidahonmachi, Sakyo Ward, Kyoto 606-8501, Japan

29 Graduate School of Public Health, Seoul National University, 1Gwanak-ro Gwanak-gu, Seoul 08826, Republic of Korea

30 Institute of Environmental Assessment and Water Research (IDAEA), Spanish Council for Scientific Research (CSIC), Jordi Girona 18-26, 08034 Barcelona, Spain

31 Department of Statistics and Computational Research, Environmental Health Joint Research Unit FISABIO-UV-UJI CIBERESP, University of Valencia, Valencia, Spain

32 Department of Public Health and Clinical Medicine, Umeå University, 90185 Umeå, Sweden

33 Swiss Tropical and Public Health Institute, Socinstrasse 57, 4051 Basel, Switzerland

34 University of Basel, Petersplatz 1, 4001 Basel, Switzerland

35 Environmental and Occupational Medicine, and Institute of Occupational Medicine and Industrial Hygiene, National Taiwan University (NTU) and NTU Hospital, 1 Section 4, Roosevelt Rd, Da'an District, Taipei, Taiwan

36 National Institute of Environmental Health Sciences, National Health Research Institutes, 35 Keyan Road, 35053 Zhunan, Taiwan

37 Department of Environmental Health, Harvard T.H. Chan School of Public Health, 677 Huntington Ave, Boston, MA 02115, USA

38 School of Forestry and Environmental Studies, Yale University, 195 Prospect St, New Haven, CT 06511 , USA

39 Faculty of Public Health, University of Medicine and Pharmacy, Ho Chi Minh city, 217 Hồng Bàng, Phường 11, Quận 5, Ho Chi Minh City, Vietnam

40 Institute of Research and Development, Duy Tan University, 254 Nguyễn Văn Linh, Thạc Gián, Q. Thanh Khê, Da Nang, Vietnam

41 Chemical and Environmental Effects, Centre for Radiation, Chemical \& Environmental Hazards, Public Health England, Didcot Oxon, Chilton, London OX11 0RQ, UK

42 Institute of Occupational Medicine, Research Avenue North, Riccarton, Edinburgh EH14 4AP, UK

43 Center for Health and the Global Environment (CHanGE), University of Washington, Seattle, WA 98105, USA 